\title{
EDITORIAL: Affordable Healthcare \& Digital Innovation
}

\author{
Mangla Mundasad, Gangadhara Bharmappanavara \& Sahana Rao
}

cite as: Mundasad M, Bharmappanavara G, Rao S. (2018) Editorial: Affordable Healthcare.

Sushruta Oct 11(1):5-6 DOI: 10.38192/11.1.1

The 2018 BAPIO Annual Conference takes a close and uncompromising look at affordable healthcare and digital innovation. These phrases are not new - indeed many of us may read them without giving a passing thought to what they really mean. They may have become the healthcare buzz words of our time. But we are sure everyone shares our hope that the first phrase 'affordable healthcare' stops being a question rather than unwavering reality. And that the second phrase, 'digital innovation' will help produce and deliver the high quality, cost effective healthcare that everyone deserves. This conference is a moment to reflect on the shape of the NHS we want to work in and the NHS we want our patients to be treated in.

For 70 years, the National Health Service has been known for its noble and coveted aims - to deliver universal health care for all, irrespective of age, race and social status. But in 2018, the very existence of the NHS is being challenged by a rising costs of services, an ageing population, lifestyle factors, successive winter crises and a marked change in public expectations. If the current situation continues without radical change, the NHS could face debts up to 30 billion pounds by 2020 (NHS Five year Forward View, May 2016), making this much loved institution unsustainable.

As innovations gather pace, the NHS is moving from a manual system towards digitalisation; the hope is this enables professionals to improve communication and patient's to access the care they need more efficiently. NHS England is fully committed to implementing collaborative and coordinated innovations and advances in digital technology (Next Step on NHS Five Year Forward View-2016; Harnessing technology and innovation). But with each new innovation comes new challenges - from privacy to budgets. The population of the UK is increasing at an average rate of $0.59 \%$ each year (worldometers.info). And at the same time, people are living longer. With these improvements in life-expectancy comes an increasing pressure on scarce resources. The NHS is facing a major workforce crisis with a reduction in staff numbers. To cope with this crisis, the NHS has been hiring staff who have trained outside the UK. Twelve and a half percent of NHS England's staff are from overseas (House of Commons Library, Number 7783 , Feb 2018). Since the referendum the number of new nurses coming from the EU to work in the UK has dropped by 87\% from 6,382 in 2016/17 to 805 in 2017/18 (Nursing and Midwifery Council; The Health Foundation).

A survey of 1720 doctors from other European Economic Area (EEA) countries working in the UK carried out by BMA at the end of last year found that almost half $(45 \%)$ were considering 
leaving as a result of the referendum vote (BMJ 2018; 361). With this current picture in mind it is an important moment for the eminent and experienced panel to enlighten us on the current healthcare workforce recruitment crisis around the world; the challenges this poses and the possible solutions it brings.

Hardly anyone will have failed to notice that the bruising junior doctor strike and the concerns raised by the Bawa-Garba case had significant impact on junior doctor morale. In his article, Dr Mehta provides unique insight \& discusses learning points from these significant moments. Recognising the need for more trainee support, this conference has a day dedicated specifically to trainees, highlighting the issues pertaining to junior doctors; discussing current and future training pathways and as a space to share learning and ideas to improve trainee morale. Meanwhile the BAPIO Research and Innovation Conference showcases some great work done by medical professionals - juniors and seniors alike.

We have eminent speakers at the conference discussing novel solutions that could make health care affordable, a critical challenge of our time. The conference also provides a great platform to interact and exchange views with BAPIO members and we hope is a moment to reflect and engage in issues that is dear to us all and an excellent learning experience from expert colleagues.

We sincerely thank our president Dr Ramesh Mehta, for supporting us with the 21st National Annual Conference. Our special thanks to Prof Parag Singhal, National Secretary and organising Chair, and everyone in the organising committee who have contributed in making this event a success. And a very special thanks to all those delegates who have made the time to come to and contribute to the conference. Hope you all have an enjoyable conference.

Links

https://www.england.nhs.uk/five-year-forward-view/

https://www.worldometers.info/world-population/uk-population/

https://commonslibrary.parliament.uk/research-briefings/cbp-7783/

https://www.bmj.com/content/361/8149

https://www.bmj.com/bawa-garba 